\title{
Towards Linking Four Emerging Paradigms in Economic Theory-Regulationist, Institutionalist, Post-modernist, and Post-development
}

\author{
MOAZAM MAHMOOD and DURR-E-NAYAB
}

\section{INTRODUCTION}

This paper is an epistemological attempt to synthesise four emerging paradigms in economic theory. These paradigms are the regulationist, the institutionalist, the post-modernist, and the post-development. Arguably, these are paradigms rather than models of behaviour because they each presents an analytical framework for examining different economic phenomena. We shall attempt to show that the four paradigms are useful, complementary, and can be symbiotically linked into a broader paradigm especially to examine the phenomenon of low growth in the region.

If we use a modified Kuhnian (1970) model for paradigmatic shifts in a discipline, we can argue that there are three dominating, competing, normal paradigms in economic theory: neoclassical, Marxist, and development theory. In Kuhnian fashion, these three dominant paradigms are pressured by several crises of inability to explain phenomena. Many of these explanational crises are about Less Industrialised Countries (LICs), but increasingly these crises are also about the inability to explain change in the Industrialised Countries (ICs) and the Newly Industrialising Countries (NICs). One, these three paradigms have to explain the differential growth rates of economies. They have to explain the low growth of LICs relative to both the old NICs (Japan, South Korea, Taiwan, Singapore, and Hong Kong) and the new NICs (Malaysia, Indonesia, Thailand, and China). The collapse of the Soviet model also has to be explained. Two, these paradigms have to explain the coexistence of significant levels of poverty with affluence in the LIs, and NICs, and now emergent poverty in the ICs. Three, these paradigms also increasingly have to explain why in a country growth and distribution is biased in favour of particular ethnic and social groups, excluding others, fuelling ethnic and social conflicts within countries and across countries globally. Four, these paradigms have to establish whether the IC market-determined patterns of consumption demand can be satisfied globally.

Moazam Mahmood is Chief of Research and Durr-e-Nayab is Staff Anthropologist at the Pakistan Institute of Development Economics, Islamabad. 
Attempts to answer these question have thrown up sets of studies which can be grouped into emerging alternative paradigms, competing with the three older dominant paradigms, and with each other. We shall examine representative literature to characterise four such recent alternative paradigms. The object of this limited exercise is not to examine each paradigm comprehensively, but to show its complementarity and linkage to the others. The resulting synthesis into a broader, more comprehensive paradigm may be more useful in analysing problems of growth in this region.

The first set of literature examined is from the regulationist school represented here by Alan Lipietz and Robert Boyer at CEPREMAP in Paris, Steve Marglin at Harvard, and Bob Rowthorn and Ajit Singh at Cambridge. This school provides a very broad-based framework for analysing a macro-economy. We feel, however, that the abstract categorisation of the regulationist school is undercut very well by the specification allowed by the institutionalist school as represented most recently by Douglas North, and earlier by Demsetz and Posner. The institutionalist school allows us to highlight a fracturing of the conventional categories of analysis like capital and labour, especially as illustrated by case-studies from Pakistan.

This fracturing of the conventional categories of analysis is explained at a global level by post-modernist theories of information processing applied to analysing economic and social change; for instance by Doug Brown. However, to explain the specific fracturing of categories like capital and labour in Pakistan, we need a recourse to the emergent post-development school, represented here by Steve Marglin, Tariq Banuri, Ashis Nandy, and Arshad Zaman. They allow us to turn the question on its head, that the question is not to search for links within fractured categories like capital and labour, but as to why there should be any links within categories fractured by the colonial impact not just on the production bases, but more fundamentally on the knowledge bases. This conceptual itinerary across four schools or nascent paradigms allow us at the end of the paper to point out useful directions for research in synthesising a broader paradigm for analysing the lack of growth in the region.

\section{THE REGULATIONIST PARADIGM}

\subsection{The Paradigm}

The neoclassical categories of analysis offer polarities, the atomistic agent, and the aggregated market environment. In contrast, the Marxist categories break ground by offering intermediate categories between the agent and the market, like capital and labour, and by offering relationships between these categories, like capital-labour relations. So the neoclassical analysis lacks intermediate categories like class, and relationships such as those between capital and labour, which the Marxist categories provide. In return, the Marxist analysis lacks a category 
characterising the micro and macro environment like the market conditions provided by the neoclassicals.

The regulationist school appears in many ways to synthesise the neoclassical and the Marxist categories of analysis in just this way. This school attempts to capture four essential environments or regimes for an economy, [Marglin (1990); Glyn et al. (1990)]:

(1) the global economy regime;

(2) the domestic accumulation regime;

(3) the production regime; and

(4) the rules of coordination regime.

The context of the development of the school helps to explain the establishment of these categories or regimes of analysis. Marglin and Glyn et al. have attempted to explain the long period of high capitalist growth for the ICs between the great depression and the global recession of the 1970s.

(1) The global regime which explains the golden age is the economic and political domination by the US of the international order. The Pax Americana ensured an orderly flow of goods between LICs and ICs, with oil pegged at about $\$ 2$ a barrel. The Bretton Woods system gave intermediate liquidity to trade through fixed exchange rates, a mid-course between the rigidity of the gold standard and the uncertainty of floating exchange rates. US advantage in the export of some commodities built up large US current account surpluses, which were invested in Europe, adding to the Marshall Plan investment. Finally, US political domination kept trade union bargaining power and wage demands low, and the profit margin up.

(2) The regime of domestic accumulation is the Keynesian element in the model, defining a set of mechanisms for managing growth of output and employment. This growth of output and employment depends on the investment demand, on the one hand, and the supply of saving, on the other hand. In the golden age, the investment demand was kept high through a high profit share, low wage demands, high productivity, and high government expenditure. High savings to match this high investment demand were ensured through the expectation of high profit rates.

(3) The regime of production is the explicitly Marxist element in the Regulationist school, defining capital labour relations. In the golden age, subordination of labour went from Fordist centralisation of production to Taylorist machine-based and rule-directed systems. The knowledge, 
authority, and responsibility of labour was replaced by the machine and the rule book.

(4) The rules of coordination is the regime by which the actions of agents, firms, and states are aligned. The regulationist school uses this element in tandem with the regimes of accumulation and production. Neoclassical theory uses a price regime to determine profits which determine capital allocation and accumulation, and wages to guide labour allocation and effort. However, the Marxists and the regulationists contend that capitalists never really rely on the price mechanism. They need to convert labour into labour power, keep the wage share low and the profit share high. This boils down to price mechanisms to control labour and its product. For this, the golden age used a variety of wage mechanisms, like efficiency wages and keeping the cost of job loss high.

The basic causal mechanism for the end of the golden age, according to this regulationist school, was full employment and high wage-led profit squeeze. This slowed down both the investment demand and savings, lowering capital accumulation, employment, and output. Bowles and Boyer (1990) attribute ultimate causality to a high employment-led decline in productivity relative to wage demands in the US and Europe. The lagging labour productivity converted the US trade surpluses and undervalued Dollar into trade deficits and an overvalued Dollar. As a result, the US pulled out from gold convertibility in 1969, and Bretton Woods was abandoned to floating exchange rates by 1973 .

\subsection{Problems with the Paradigm}

For our purposes these four regimes provide a broad-based framework to analyse a micro or macro economy. However, this hybrid school shares a major problem with its neoclassical and Marxist predecessors in that the categories that it offers for analysis, the regimes, are still too abstract.

The neoclassical categories of the agent and the market, the Marxist categories of capital, labour, the mode of production, and the state, and the regulationist regimes of the global economy, domestic accumulation, production, and rules of coordination, all synthesised together, give a nested set of categories. Beginning at the atomistic level, the agent operates within a class, controlled by the regime of production and rules of coordination. Both the agent and his product enter the labour and commodity markets simultaneously. The mode of production determines the technology and the product mixes and productivities. At the level of the regime of accumulation, the production and coordination regimes and the mode of production determine the macro conditions of profitwages and savings-investment. Finally, all these environments are nested and coordinated with the global economy. 
All these nested categories would appear to give a wealth of detail about behaviour at each level. However, a critical determinant of behaviour which is still missing is the social constraints. This critical variable of constraints is provided by the literature on institutions.

\section{THE INSTITUTIONAL PARADIGM}

\subsection{The Paradigm}

Institutional theory initially emerges from the neoclassical dilemma of the need to reduce externalities of the firm [Coase (1937)]. Demsetz (1967) argues that it is the change in the institution of property rights that allows externalities to be internalised within the new property rights. Therefore, property rights change to increase economic efficiency. North and Thomas (1973) give the example that property rights will tend to move towards private property. The argument is that jointly owned property has high transaction costs in sharing inputs and output, which reduce the owner's incentive for investing in technical change on the land. An institutional change towards private property reduces the transaction costs entailed by joint property, and increases the owner's incentive to invest in technical change. Institutional change, therefore, moves towards efficiency.

The argument that emerges for our purposes is that property rights illustrate that institutions are man-made constraints imposed on economic functioning, or, more broadly, on social interaction. Therefore, institutions are a critical variable that constrains growth. North (1992) uses a formal definition that institutions define and limit the choice set of individuals.

The central question then for North (1992), and for us, is the need to explain the divergent growth paths of economies, when international trade theory argues for convergence. North's formulation of the problem is that growth theorists like Kuznets, Dennison, and Abramovitz trace growth causally to the sources of productivity growth. These sources of productivity growth are modelled in a zero transaction cost world, which is to depend on the stock of knowledge applied to physical and human capital. This model of course gives an upper bound to growth, or potential growth. The dilemma for North is: Why is this potential for growth not fulfilled in some cases? North's hunch is that the model makes a critical assumption of a common incentive structure. The structure of incentives and constraints built into institutions should explain divergent growth paths for economies.

The question now becomes twofold. If there are efficient and inefficient institutions, first, why do inefficient institutions arise, and second, why does competition not drive out inefficient institutions over time [North and Thomas (1973)]? 
North's answer to the first question, of the origin of inefficient institutions, is that rulers devise property rights in their own interests, which entail transaction costs, which demarcate inefficient institutions [North (1981)]. This is a definitional identity.

North's answer to the second question is more complex, less tautological (1992). He makes a crucial distinction between institutions and organisations. Organisations are defined as groups of individuals bound by common objectives, including political bodies like parties and parliament, economic bodies like firms and trade unions, educational bodies like schools and universities, and social bodies like trade associations. Institutions are defined as the rules that give a structure of incentives and constraints. Institutions and organisations then interact, with the institutional structure determining organisations, which in turn influence institutional change.

North (1992) argues that in a zero-transaction costs world, political and economic markets are efficient because agents either have true models or, even if initially incorrect models, the information feedback corrects them. However, North rejects the rational agent model, choosing the alternative set of premises:

(i) agents often act on incomplete information; and

(ii) agents process this information often on imperfect subjective models.

Therefore, North's answer is that transaction costs in political and economic markets lead to inefficient property rights, and agents' imperfect subjective models lead to the persistence of such inefficient property rights.

North (1992) further divides the institutional matrix of an economy into two parts, informal constraints and transaction costs. Informal constraints are the cultural values transmitted. Transaction costs, such as those in the political market, when high, give political actors autonomy from their constituents, and so lower the incentives for radical political and economic change.

\subsection{The Linkage}

Institutional theory is nascent and weak, but it makes one argument which is important for us, that an economy's potential growth is constrained by its institutional matrix of incentives and constraints. By analogy, going from the macro to the meso and micro levels, the nested abstract categories given to us by the neoclassical, Marxist, and regulationist schools all need to be constrained by the institutional-organisational interaction operating in them. Applying the constraints of institutions to these categories produces a very interesting result of fracturing the categories. As instances for the argument, we can take the categories of the global economy, and capital, labour, and the state in Pakistan. Constraining the operation of these categories through institutional specification gives them tendencies contrary to the expected, and/or splits the categories with divergent trends within the same category. 
(i) At the level of the global economy, neoclassical theory accepts de facto, while Marxist theory posits de jure, that capital-labour relations are conflictual. Both Europe and the US adopted a capital-labour relations regime which is Fordist and Taylorist, and so deskills labour. However, the Japanese production regime never became wholly Taylorist, preferring instead a familial concept of employment given by the indigenous culture [Marglin (1990)]. This concept of familial capital-labour relations then becomes the centre piece of the new Japanese production regime based on flexible specialisation, labour reskilling, workers' innovations, 'Kanban' just in time reduced inventories, batches of one, and total quality control [Piore and Sabel (1984)]. Labour is reskilled, re-authorised, and responsibilised. This Japanese regime of capital-labour relations is now held to be a critical element in the continuation of Japanese export-led growth while the ICs golden age faded. As such, it has had important demonstration effects on the designing of cooperative capital-labour institutions in Scandinavia and Northern Italy.

(ii) In Pakistan, the category of industrial production capital does not appear to be homogenous. Institutional specification instead shows several divergent interests in production capital, fracturing the class.

(a) Industrial production capital appears riven into at least two dominant regional groups, the larger being Punjab-based capital, and the smaller being Frontier-based capital. Industrial production capital, with a theoretically posited homogeneity of interests, is fractured along regional and ethnic lines in Pakistan. The split becomes evident when the state allocates fiscal and infrastructural incentives to the two regions.

(b) A more momentous fracturing is evident in industrial production capital in Pakistan between the large-scale and the small-scale sectors. The small-scale sector, which employs 75 percent of the industrial population, is clearly starved for formal credit and capital assets to boost its productivity and income. It has a share of only 2 percent each in the formal credit and the total capital assets. The growth of employment, productivity, and income of the predominant population in industry is, thus, blocked by institutional fracturing of the category of production capital.

(iii) The category of industrial labour is also fractured into the large- and smallscale sectors. 25 percent of industrial labour, employed by the large-scale sector having higher productivity, wages, and growth in these variables, can be organised by law, have union representation, and considerable welfare 
benefits, relative to the 75 percent who remain unorganised, unrepresented, and have no benefits. Social welfare proposals made for the informal smallscale sector's labour are strongly resisted by the union representation of the organised large-scale sector, and by the International Labour Organisation, under the guise of the need for welfare deepening before welfare widening [Mahmood (1994)]. Again the fracturing of class interests is seen to inhibit the growth of real incomes and the welfare of the predominant industrial population.

(iv) A final instance of the institutional fracturing of categories can be given here for the state in Pakistan. Political theories about the lack of governance by the state abound, but our concern here is to discern evidence of the fracturing of interests in the state. We can define, somewhat simplistically, the designated function of the state to be decision-making in order to increase welfare. We can also posit that some proportion of state employees use this objective function. Alternatively, we can posit another objective function of state employees to be decision-making in order to seek rents, direct or indirect, from the control of access to a resource.

Now the state's decision-makers comprise professionals and politicians. Our tentative argument is that the state's decision-makers are split between the two objective functions of welfare-enhancing and rent-seeking. The fractured state causes problems of governance, inefficiency, and loss of welfare for the population.

\subsection{Problems with the Institutional Paradigm}

The institutional school allows us to add specificity to the abstract categories developed so far. Adding this institutional specificity shows that these categories, instanced by global capital labour regimes, and the categories of industrial capital and labour, and the state in Pakistan are fractured. Moreover, this fracturing has major loss of welfare implications. The institutional school, however, does not help us to determine what causal factors contribute to this fracturing of categories. This causality is provided by two other schools, at a global level by post-modernism as applied to economic theory, and for LICs by post-development theory.

\section{POST-MODERNISM}

\subsection{The Paradigm}

Post-modernism holds that the traditional categories of analysis offered by modernist schools have been fractured. To examine the causal factors offered for this fracturing, we shall only use elements from the vast discourse which can be applied to economic theory, as done for instance by Brown (1991). 
Post-modernism argues at a global level that the technological revolution after World War II has led to a global economic restructuring which fragments the categories of capitalism offered by the grand narratives of the market and class [Brown (1991)]. The causal arguments for this fragmentation of categories work on two levels:

(i) economic restructuring; and

(ii) consciousness of phenomena, with implications for theories of knowledge.

\section{(i) Economic Restructuring}

The primacy of technical change is advocated by the instrumentalist value theory of Ayres [Harvey (1989)]. This position argues that the profit squeeze of the 1960s, combined with technical change in electronics, has led to a speeding-up of turnover time in production and consumption to increase profits. This, in turn, implies volatility in demand patterns, and accordingly restructuring of production away from the mass consumption and production systems to post-Fordist Flexible Specialisation systems, as seen above in the discussion on the Japanese production regime.

\section{(ii) Consciousness of Phenomena with Implications for Theories of Knowledge}

(a) Post-modernism asserts a major philosophical postulate that there is no reality, physical or social, independent of the analytical tools used to perceive it [Nell (1980)]. A social category will capture as much detail as it is designed for. If a category is defined abstractly, it will not capture specificities like institutional fracturing. If institutional detail is specified in defining the category, then institutional fracturing can be found if it occurs.

(b) Technical change and accelerated turnover time have another major implication for consciousness of phenomena. Accelerated turnover time implies that there is a greater probability that we can experience the world differently from others. This fragments our experience of capitalism, implying multiple visions of reality rather than a single grand vision. Fragmentation of experience also dovetails with a multi-causal theory of phenomena, rather than a mono-causal one. The implication of these arguments is again a fragmentation of the categories of capitalism.

\subsection{The Problems with Global Post-modernism}

The version of post-modernism seen here offers an explanation for the fragmentation of the categories of capitalism at a very abstract and global level. The primacy of technical change in the explanation also makes it more relevant in 
analysing ICs rather than LICs. So it explains the fragmentation noted in global production regimes, between the Fordist-Taylorist production systems in the US and the familial, flexible-specialisation, labour-reskilling production systems in Japan. However, it does not explain the institutional fracturing of the categories of industrial capital, labour, and the state, as seen in Pakistan, which is not subject to such major technical change. This explanation for the fracturing of our analytical categories in the LICs can be attempted using the very nascent paradigm of postdevelopment theory.

\section{POST-DEVELOPMENT THEORY}

\subsection{The Paradigm}

While post-modernism attacks the grand narratives of the project of modernisation, post-development theory with some lineage to post-modernism focuses its criticism on the more recent project of development in the LICs.

The post-development school actually offers two linkages to our synthetic, broader paradigm of nested categories. One, it can be used to explain the fracturing of our categories of capital, labour, and the state in Pakistan and, where applicable, in the other LICs. Two, it adds a very important category of analysis to our synthetic paradigm: the growth of the macro and micro economy's indigenous knowledge base, and its application to the three domestic regimes of accumulation, production, and the rules of coordination.

The post-development school can be used to argue that the categories of capital, labour, the state, and the entire institutional matrix of an LIC will tend to be fractured by its colonial experience and, more importantly, by its subsequent development experience [Marglin (1991); Banuri (1991)]. The development experience will tend to fracture the institutional matrix of the LIC into traditional and modern sectors, with the traditional sector involuting, and the modern sector stripped of its indigenous cultural institutions and knowledge systems.

The logic of the argument is the following.

Development theory, a paradigm for economic change evolving since World War II, argues that growth without development and modernisation is an insufficient condition for either growth or welfare [Marglin (1991)]. The reason is that unless growth is complemented by change in the economic, political, social, and cultural infrastructure - that is, institutional change, growth and increase in welfare will be transitory. The end state of development, variously defined as growth with redistribution by Little, basic needs by Streeten, and levels of individual capabilities by Sen, requires a process of modernisation. This process of modernisation implies economic change through structural transformation of industry and agriculture, political change through rationalisation of authority and a rational bureaucracy, 
social change through weakening of ascriptive ties, and cultural change through secularisation and science. The post-development school argues that the package of growth must be decoupled from the package of development, modernisation, and entailed institutional change [Marglin (1991); Banuri (1991)]. There are several arguments why the package of development, modernisation, and entailed institutional change is neither necessary nor a good for an LIC.

(i) The first step in the argument is that the project of development, modernisation, and entailed institutional change is Eurocentric, based on a solipsism, and therefore has a linear view of social progress. The metaphor of development implies that the ICs are the end state, which gives a linear path that LICs must follow, and their progress be judged by the distance covered.

(ii) The second step in the argument is that culture is a set of knowledge systems, characterised by their own epistemology, and rules for transmission, innovation, and power relations.

(iii) The third step in the argument is that the political dominance of the ICs in the West gives them intellectual dominance over the LICs' cultural knowledge systems [Banuri (1991)]. This has two major implications. One, the package of development, modernisation, and entailed institutional change imposed on the LICs is the Eurocentric one, rather than their own indigenous culture-based knowledge systems. Two, when we apply this to our synthetic paradigm of nested categories, we know that institutions must nest in the domestic regimes of accumulation, production, and rules of coordination to determine growth paths. The Japanese example of a familial institution of employment used in the regime of production, and its success, illustrates the importance of indigenous institutions in determining growth.

(iv) The fourth step in the argument is that the project of development and modernisation entails institutional change in the LICs, which fractures the institutional matrix of the economy. Using North's differentiation of the institutional matrix into organisations and the interacting institutional framework, development and modernisation fractures these organisations and the institutional framework into modern and traditional sectors. The modern sector is based on borrowed Eurocentric knowledge systems, while the traditional sector is based on indigenous knowledge systems. More importantly, the modern institutional choice set expands with development, while the traditional choice set shrinks [Marglin (1991)]. The traditional choice set shrinks because it is starved for resources and the cultural space that it needs to evolve, while the modern choice set is often imposed coercively on a reluctant population [Marglin (1991)]. 


\subsection{Linkages}

So post-development theory provides us with a good explanation of why the categories of capital and labour were seen to fracture in the case of Pakistan. Capital in the modern large-scale sector in Pakistan has the access to formal marketsubsidised credit, imported technology, and Western production systems, which allow it to expand its productivity and profits but keeping its employment levels almost constant. Whereas capital in the traditional small-scale sector has no access to formal market-subsidised credit; in consequence, it resorts to high-interest informal market credit, uses in large part indigenous atrophying technology, is based on family labour, and has low productivity and profits. Development and neoclassical theory is misplaced if it recommends that the traditional small-scale sector can only grow by subcontracting links to the large-scale sector. We would argue that this strategy would simply lead to the large-scale sector exploiting the cheap family labour of the small-scale sector. Alternatively, the small-scale traditional sector should be given access to credit and appropriate institutional support, which will allow it to innovate its indigenous technology and production systems, which have been stagnating for lack of resources and cultural space and support.

This argument by symmetry applies to the fractured category of labour in Pakistan as well. Labour in the predominant small-scale sector will gain more through the autonomous growth of the sector rather than through its growth as an auxiliary sector for the large-scale sector. The question of the trade unions constraining the expansion of organising legislation and the social welfare benefits to the small-scale informal sector labour is a more complex one, and needs to be examined along with the posited fracturing of the state in Pakistan.

We have posited that the state fractures on the basis of two objective functions, i.e., decision-making to increase welfare and decision-making for rentseeking. Perhaps the role of trade unions reluctant to expand rights and welfare to the informal sector also puts them into the same set as the state. Trade unions can either work to enhance welfare, or they can seek rents. Extension of rights and benefits to the majority of labour in the small-scale sector would be welfareenhancing; constraining this extension implies rent-seeking.

The question then remains as to why this expanded definition of the state is fractured by these two objective functions. Post-development theory again provides an analogy to this fracturing. The objective function of decision-making to increase welfare perhaps belongs to a more traditional indigenous cultural concept of the state's primary function. The objective function of decision-making for rent-seeking is closer to a modern private firm's objective function. The demonstration effect of the modern private sector firms' objective function is driving up the incidence of rent-seeking in the state. The traditional objective function of welfare is shrinking in the state. 
Finally, post-development theory adds a critical category to our synthetic paradigm of nested categories, that of the use of indigenous knowledge systems in the three domestic regimes of accumulation, production, and the rules of coordination. Banuri (1991a) argues that non-Western cultural maps are more balanced between the impersonal and the personal, and so would promote more cohesion. This use of the traditional choice set would, therefore, offer more cooperative solutions in production systems.

\section{CONCLUSIONS}

The objective of this paper has not been a formal critical interpretation of the literature. The objective has been to look for symmetries and complementarities between four emerging paradigms in economic theory. The methodology has been to identify analytical categories which are useful in characterising a micro or macro economy to determine its growth. This gives a synthetic paradigm of nested categories.

The neoclassical paradigm gives the polar categories of the agent and the market. The Marxist paradigm gives the intermediate categories of class relations between capital and labour, the mode of production, and the state. The regulationist school offers a grand synthesis of regimes that characterise an economy, the global economy regime, the regime of accumulation, the regime of production, and the regime of the rules of coordination.

These nested abstract categories are given local specificity and constraints by the institutional school. Institutional specification allows us to capture a very interesting fracturing of categories for capital, labour, and the state in the case of Pakistan.

This fracturing of categories is explained by two schools: at the global abstract level, by the post-modernist school; and for the LICs, by the postdevelopment school. The post-modern school attributes fracturing of the categories of capitalism to a complex combination of global restructuring, accelerated turnover time reducing shared experience and so fragmenting reality, and the assertion of more subjective theories of consciousness.

The post-development school argues that the project of development is Eurocentric politically, and therefore intellectually dominant and coercive. It splits the institutional matrix of the LIC into expanding modern choice sets and shrinking traditional choice sets. The post-development school argues for the need of cultural space to develop indigenous knowledge systems. It adds an important category to our synthetic paradigm of nested categories, that of the application of indigenous knowledge systems to the three domestic regimes of accumulation, production, and rules of coordination. 
This extremely limited exercise leaves us a large agenda for research. One point of departure for research is Nandy's (1983) definition of progress as the expansion of awareness of exploitation. This perspective transforms the role of intervention and knowledge systems, which become the new research priorities.

\section{REFERENCES}

Banuri, T. (1991) Development and the Politics of Knowledge-A Critical Interpretation of the Social Role of Modernisation Theories in the Development of the Third World. In S. Marglin and F. Marglin (eds) Dominating Knowledge-Development Culture and Resistance. Oxford: Clarendon.

Banuri, T. (1991a) Modernisation and its Discontents: A Cultural Perspective. In. S. Marglin and F. Marglin (eds) op. cit.

Bowles, S., and R. Boyer (1990) A Wage-Led Employment Regime: Income Distribution, Labour Discipline, and Aggregate Demand in Welfare Capitalism. In S. Marglin and J. Schor (eds) The Golden Age of CapitalismReinterpreting the Postwar Experience. Oxford: Clarendon.

Brown, D. (1991) An Institutionalist Look at Post-modernism. Journal of Economic Issues 25:4.

Coase, R. (1937) The Nature of the Firm. Economica November.

Demsetz, H. (1967) Towards a Theory of Property Rights. American Economic Review Papers and Proceedings of Annual Conference.

Glyn, A. Hughes, A. Lipietz A., and A. Singh (1990) The Rise and Fall of the Golden Age. In S. Marglin and J. Schor (eds) op.cit.

Harvey, David (1989) The Post-modern Condition: An Enquiry into the Origins of Cultural Change. Cambridge, Mass.: Basil Blackwell.

Kuhn, T. S. (1970) The Structure of Scientific Revolutions. Chicago: University of Chicago Press.

Mahmood, M. (1994) Extending the Coverage of Social Welfare Benefits. Unpublished paper presented at a seminar at the Sustainable Development Policy Institute, Islamabad.

Marglin, S. (1990) Lessons of the Golden Age-An Overview. In S. Marglin and J. Schor (eds) op.cit.

Marglin, S. (1991) Towards a Decolonisation of the Mind. In S. Marglin and F. Marglin (eds) op.cit.

Nandy, A. (1983) The Intimate Enemy. Delhi: Oxford University Press.

Nell, E. J. (1980) Growth Profits and Property. Cambridge: Cambridge University Press.

North, D. (1981) Structure and Change in Economic History. Norton. 
North, D. (1992) Institutions, Institutional Change, and Economic Performance. Cambridge: Cambridge University Press.

North, D., and Thomas (1973) The Rise of the Western World-A New Economic History. Cambridge: Cambridge University Press.

Piore, M., and F. Sabel (1984) The Second Industrial Divide: Possibilities of Prosperity. Basic Books. 